\title{
An approach for assessing the vulnerability of the water resources of Yemen to climate change
}

\author{
A hmed Alderwish ${ }^{1, *}$, M ohamed Al-Eryani ${ }^{2}$ \\ ${ }^{1}$ Earth and Environmental Sciences Department, Sana'a University, PO Box 13743, Yemen \\ ${ }^{2} \mathrm{C}$ ivil Engineering Department, Sana'a University, PO Box 2610, Yemen
}

\begin{abstract}
This paper outlines the methodology followed in the study of climate change impact on water resources in Yemen and presents initial results on the vulnerability of the water resources system. The selected modeling strategy is used for the first time in climate change assessment studies and is briefly discussed. This strategy comprised 4 interacting models: a Rainfall-Runoff M odel (RRM), an Irrigation Simulation Model (ISM), a Groundwater Simulation Model (GSM), and an Economic Policy M odel (EPM). A dequate indication of the water system's sensitivity to climate change in arid and semiarid regions can only be achieved when appropriate temporal and spatial scales of the assessment are used. For instance, only hourly or daily time step models can capture climate impacts on floods of ephemeral wadis. The degree of accuracy required should also be determined by the scarcity/availability of the resources.
\end{abstract}

KEY WORDS: Climate change $\cdot$ M odeling $\cdot$ Climate scenarios $\cdot$ M anagement

\section{INTRODUCTION}

The study area was selected as a case study to investigate the potential vulnerability of Yemen water resources to climate change. The area (Fig. 1) is part of the southwestern drainage basin of Yemen and covers wadi catchments that originate within the higher rainfall areas of the southern highlands and midlands of the country and drain toward the Gulf of Aden coastal plain. The study basin comprises Wadi Bana and Wadi Hassan (together comprising $7400 \mathrm{~km}^{2}$ ) and Abyan Delta $\left(6100 \mathrm{~km}^{2}\right)$. Wadi Bana and Hassan represent the high and mountainous area (upper catchment), whereas Abyan Delta is the intermediate low coastal plain (lower catchment). The study area has special social and economical importance not only because it encompasses the main well field that supplies water to Greater Aden but also because it includes major agricultural activity. The upper reaches of the wadis are well populated and agriculturally developed.

This paper discusses the elements pertinent to the technique selected for assessing the gains and losses for water resources and water management as a result of global climate change.

*E-mail: alderwish@hotmail.com

\section{INVESTIGATIVE PROCEDURE}

To investigate the potential vulnerability of Yemen's water resources to climate change, 4 interacting components of the water resource management model were developed (Fig. 2): a Rainfall-Runoff M odel (RRM ), an Irrigation Simulation M odel (ISM ), a Groundwater Simulation Model (GSM), and an Economic Policy Model (EPM). The simulation models, although created as stand-alone models, complement each other, and linking routines can be easily implemented. A brief description for each model is given below.

\subsection{The Rainfall-Runoff M odel}

The US Soil Conservation Service (SCS 1964, 1972) method was used to model runoff response to rainfall in the study area. It is believed that this model offers a realistic interpretation of the hydrological processes experienced in Yemen (TSHWC 1993a). The model is relatively simple, using the tried and tested SCS method of estimating daily runoff volumes from rainfall, along with 2 linear reservoirs to represent soil and alluvial baseflow stores. The model attempts to represent the likely variability in runoff response over a catchment by using up to 8 runoff characteristic types in any wadi and by using 
(a)

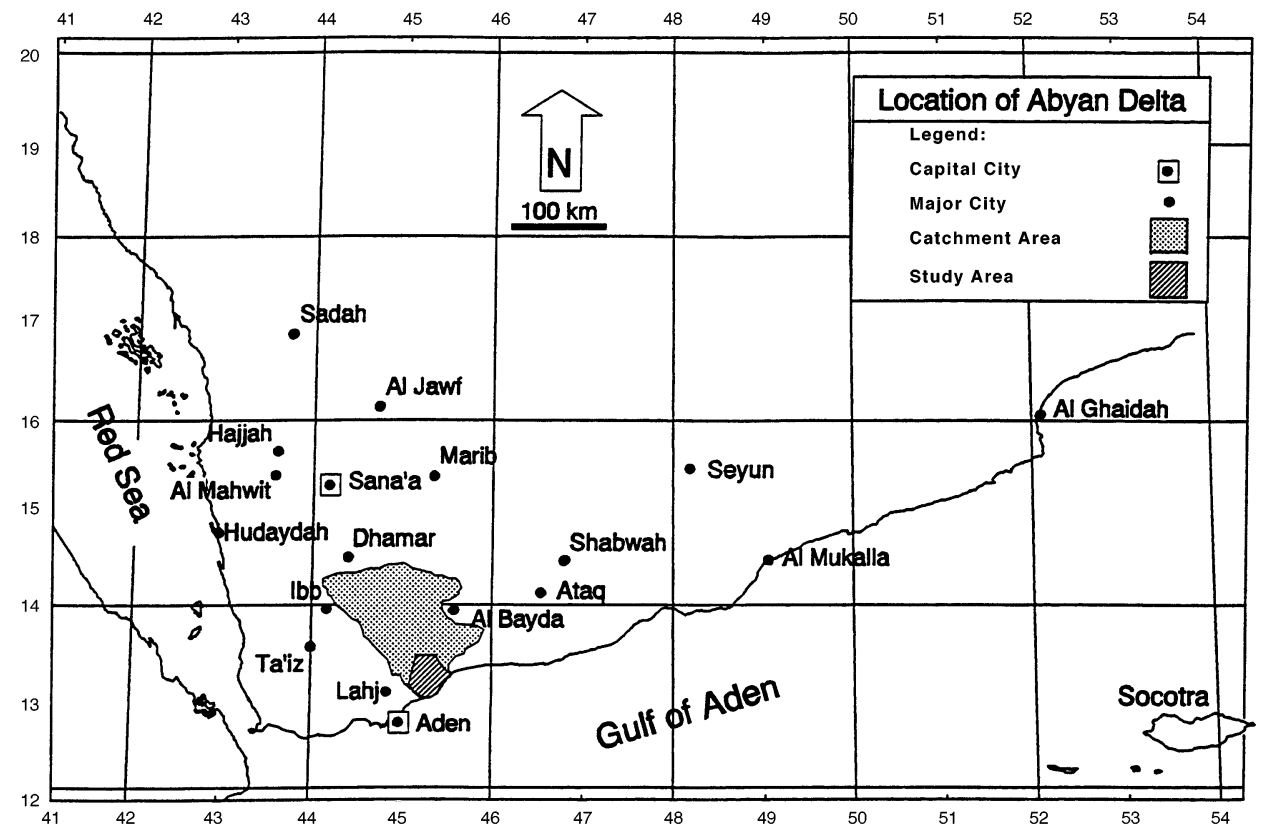

(b)

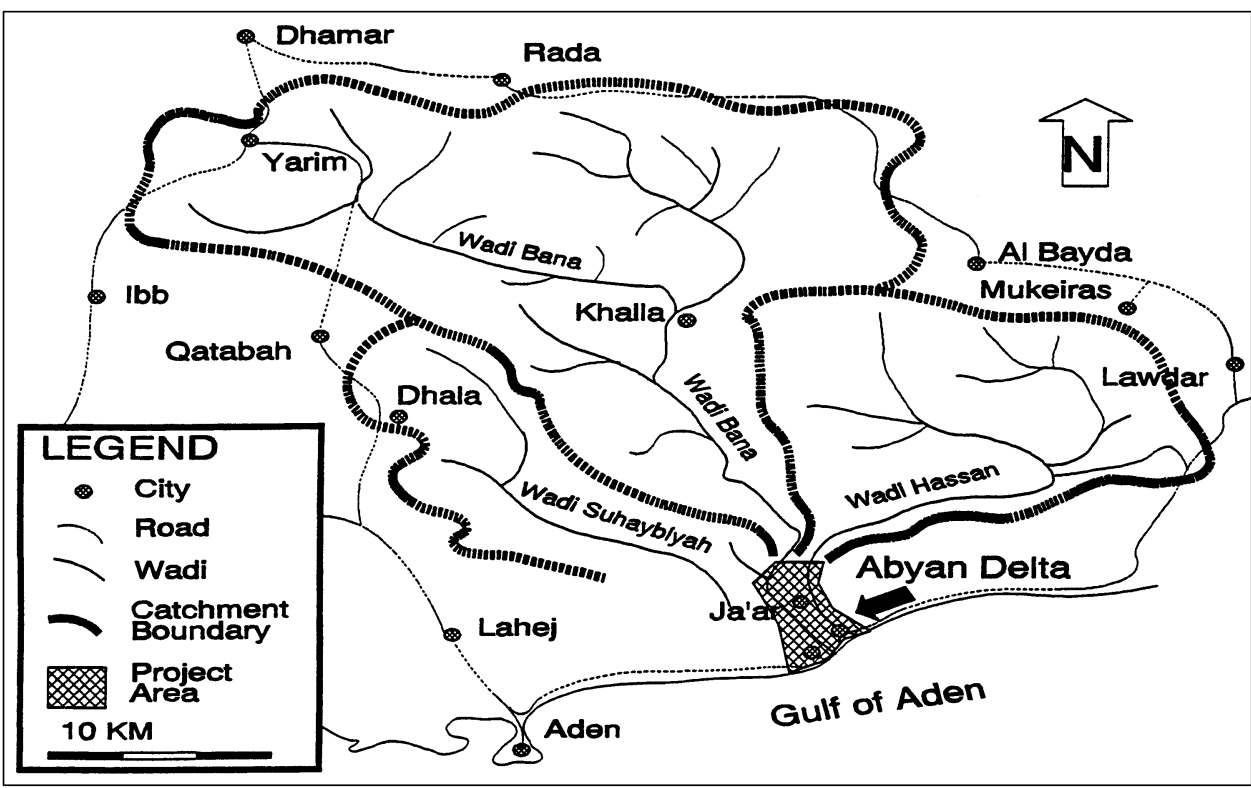

Fig. 1. (a) Location and (b) map of the Abyan Delta and its contributing catchment in Yemen

a distributed rainfall input. The runoff response to rainfall is varied according to the moisture status for the preceding $10 \mathrm{~d}$ for each runoff characteristic zone type using a simple function of curve number and antecedent rainfalls. The model has been shown to produce correct volumes of runoff for the western wadis of the country, where data are more abundant for verification (TSHWC 1993a). With slight modification, a similar model has been successfully used in Sana'a Basin to estimate daily runoff (Alderwish \& Dottridge 1995a).

\subsection{The Irrigation Simulation M odel}

The ISM was designed to estimate the quantity and timing of groundwater recharge, abstractions (amount of water pumped from wells), and crop water use and yields based on wadi flood flows and on the size of the irrigated area and groundwater pumping. It provides an analysis of the quantitative interaction of surface and groundwater so as to produce a time series of groundwater abstraction and recharge estimates re- 
sponsive to the variations in surface water supply and rainfall. Further description of this model can be found in van der Gun (1991) and TSHWC (1993b).

\subsection{The Groundwater Simulation M odel}

For modeling of groundwater flow, a distributed differential model, which is the most sophisticated of the modeling methods, was selected. The catchment behavior is represented in differential form in both space and time. This modeling strategy was selected because of the nature of the hydrological processes encountered in arid areas and their high spatial and temporal variation. The distributed differential model was the first attempt ever to be used in climate change impact studies (Feenstra \& Short 1996). MODFLOW code was chosen due to team experience, and further description of this model can be found in Alderwish \& Dottridge (1995b). The model makes it possible to assess the long- and short-term groundwater yield in the study area, the aquifer response to climate changes, and the adapted measures.

\subsection{The Economic Policy Model}

The EPM is an optimization model that is used to examine the system response to various economic policies. Linear programming (LP) is used to formulate the EPM. The model can be used as an effective tool to analyze the impact of a variety of water management strategies and economic policy measures on resource allocation and regional economic development. Although it can be in the form of a goal programming method (Goodman 1984) that uses LP and permits consideration of multiple objectives (because the method facilitates the simultaneous incorporation of several desired objectives), more simplified representation of the physical scheme and processes can be used by concentrating more on characterizing the agricultural features of the area. Water demand in the agricultural sector consumes more than $90 \%$ of the total water resources of the country. The industrial and municipal water demands can be externally supplied to the model with corresponding objective function values to evaluate the water trade-off possibilities among different consuming sectors.

\section{RESULTS}

The runoff of Wadi Bana is characterized by frequent flood peaks and steep recessions (flash floods). For baseline conditions, the mean annual runoff is

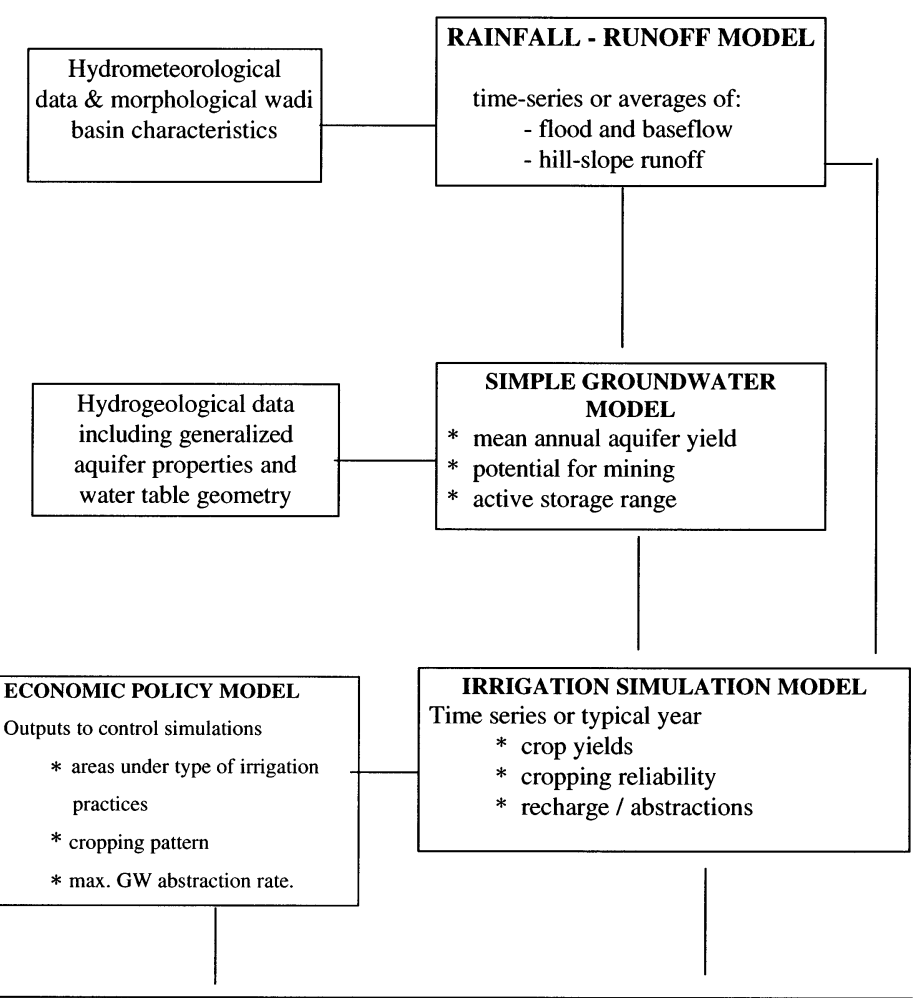

WADI BASIN WATER RESOURCES SIMULATION MODEL

Fig. 2. Components of the water resources management model of the study area

$162 \mathrm{Mm}^{3}$, or $6 \%$ of the estimated catchment rainfall, and for Wadi Hassan is $40 \mathrm{M} \mathrm{m}^{3} \mathrm{yr}^{-1}$. The number of floods per year can be quite high, with an annual average of 19 floods (Atkins \& Binnie 1984). M ean annual peak flood is $980 \mathrm{~m}^{3} \mathrm{~s}^{-1}$, and baseflow amounts to about $400 \mathrm{M} \mathrm{m}^{3} \mathrm{yr}^{-1}$ (Negenman 1995). Some $90 \%$ of the runoff goes to irrigation, of which $66 \%$ is used during the 'Kharif' irrigation season (1 J uly to 15 October) and the rest during the 'Saif' season (16 March to 31 $M$ ay). The total volume of groundwater abstraction for current condition is estimated to be $86.4 \mathrm{Mm}^{3} \mathrm{yr}^{-1}$. About $74.9 \mathrm{M} \mathrm{m}^{3} \mathrm{yr}^{-1}$ is used for irrigation (3700 to $3900 \mathrm{ha}$ ), and $11.5 \mathrm{M} \mathrm{m}^{3} \mathrm{yr}^{-1}$ for public water supply. Continuous storage depletion of the groundwater reservoir has been estimated to range between 10 and $15 \mathrm{M} \mathrm{m}^{3} \mathrm{yr}^{-1}$ based on the decline of the piezometric levels and water balance equation, respectively.

Table 1 lists current climate values together with values from 3 climate change scenarios for the study basin. Table 2 lists the values of surface water resources in the study area under current conditions and under climate change. In the opinion of Yemen climatologists, it is advisable (for the climate trend in Yemen) to expect climate change as predicted by the Oregon State University (OSU) model. With intermediate $\mathrm{CO}_{2}$ concentration levels, the OSU model predicts 
Table 1. Changes in average temperature and precipitation and generated runoff as compared with current values (baseline condition) according to the GCM models used

\begin{tabular}{|c|c|c|c|c|}
\hline Month & OSU & ECHAM 3TR & UKHI & $\begin{array}{l}\text { Baseline } \\
\text { condition }\end{array}$ \\
\hline \multicolumn{5}{|c|}{ A verage daily air temperature $\left({ }^{\circ} \mathrm{C}\right)$} \\
\hline 1 & 1.85 & 1.60 & 2.35 & 17.5 \\
\hline 2 & 1.80 & 1.45 & 2.20 & 17.7 \\
\hline 3 & 1.60 & 2.00 & 2.70 & 19.3 \\
\hline 4 & 1.70 & 1.85 & 2.50 & 20.8 \\
\hline 5 & 1.40 & 2.10 & 2.90 & 22.3 \\
\hline 6 & 1.85 & 2.10 & 3.70 & 23.2 \\
\hline 7 & 1.80 & 1.90 & 3.15 & 23.7 \\
\hline 8 & 1.85 & 2.45 & 2.00 & 23.3 \\
\hline 9 & 1.50 & 3.00 & 2.10 & 21.8 \\
\hline 10 & 1.75 & 2.40 & 1.80 & 19.1 \\
\hline 11 & 1.70 & 1.95 & 1.20 & 17.6 \\
\hline 12 & 1.60 & 2.10 & 2.10 & 16.7 \\
\hline \multicolumn{5}{|c|}{ Precipitation ratio (mm) } \\
\hline 1 & 0.92 & 0.77 & 0.82 & 12.1 \\
\hline 2 & 1.22 & 0.92 & 0.41 & 23.0 \\
\hline 3 & 1.09 & 0.84 & 1.46 & 66.4 \\
\hline 4 & 1.26 & 0.92 & 0.92 & 62.1 \\
\hline 5 & 1.25 & 0.78 & 0.86 & 60.9 \\
\hline 6 & 0.88 & 0.75 & 0.68 & 23.4 \\
\hline 7 & 1.01 & 0.93 & 2.18 & 63.9 \\
\hline 8 & 1.19 & 0.73 & 3.56 & 110.6 \\
\hline 9 & 1.12 & 0.76 & 1.83 & 25.8 \\
\hline 10 & 1.03 & 1.28 & 2.22 & 10.0 \\
\hline 11 & 1.00 & 1.02 & 2.59 & 5.7 \\
\hline 12 & 0.98 & 1.07 & 2.95 & 4.6 \\
\hline
\end{tabular}

an increase of $14 \%$ in the runoff volume by year 2050 . The UKHI model predicts an increase of $86 \%$ of flood volume, whereas the ECHAM 3TR model predicts a $6 \%$ decrease in surface water resources. UKHI and ECHAM 3TR were selected to be included because they represent the wettest and driest conditions among 14 GCM models tested, respectively.

These results should be considered preliminary, especially in regard to their application in predicting the available water resources of the study area under future climate change. This arises because the GCMs predict future climate change only on longer time intervals (no less than $1 \mathrm{mo}$ ). In arid and semi-arid areas, the spatial and temporal distribution of hydro- logical events is quite variable; hence, for reliable results, shorter time intervals (for example, daily) should be used to represent hydrological processes. This is in agreement with the statement that hydroclimatic conditions are the controlling factor in defining the scope of analysis and analytical technique to be selected. Furthermore, the abundance or scarcity of the resources is believed to control the accuracy of the results required, which, in turn, affects the choice of technique to be used. That is, the more limited the resources, the more accuracy required.

The area's water resources generally suffer from mounting pressure because of population growth, agricultural expansion, and industrial growth (which is usually a sign of 'progress'). Numerous water use conflicts are expected to emerge or will become worse. The vulnerability of the water resource system in the study basin is evident from over-exploitation of groundwater resources and the high variability of the surface water system, leading to grave problems of depletion and rising water cost.

The need for rational use of water resources in Yemen becomes even more urgent in view of the potential anthropogenically induced climate change, and such a strategy should be accepted as the water management policy in the country, as several adverse effects (such as desertification) could become more widespread. Investigations for the assessment of adaptation measures are being undertaken.

\section{DISCUSSION}

The management model is an effective tool for assessing the water resource impact and adaptation to climate change as it allows assessment of vulnerability as well as evaluation of adaptation measures. Interlinking the model components allows results and their reliability to be improved through the continuous interaction between the various components. The techniques of simulation and optimization may be employed in deriving their outputs. Linked application of the EPM with ISM and GSM will yield predictions that are more meaningful in the formulation of a water management policy, compared with predictions based

Table 2. Surface water resources in Abyan Delta under current conditions and under various scenarios $\left(\mathrm{M} \mathrm{m}^{3}\right)$

\begin{tabular}{|lcccccccccrrr|}
\hline Scenario & Jan & Feb & Mar & Apr & May & Jun & Jul & Aug & Sep & Oct & Nov & Dec \\
\hline OSU & 2.4 & 1.6 & 4.9 & 31.6 & 23.5 & 6.2 & 27.9 & 80.8 & 37.8 & 7.9 & 3.1 & 2.7 \\
UKHI & 2.0 & 1.2 & 3.8 & 22.9 & 14.5 & 5.2 & 25.5 & 49.7 & 25.6 & 9.8 & 3.2 & 3.1 \\
ECHAM 3TR & 2.2 & 0.6 & 6.6 & 23.2 & 16.1 & 4.7 & 60.1 & 241.7 & 62.1 & 17.1 & 8.1 & 8.5 \\
Baseline & 2.6 & 1.3 & 4.6 & 25.1 & 18.7 & 6.9 & 27.6 & 67.9 & 33.8 & 7.6 & 3.1 & 2.9 \\
\hline
\end{tabular}


on trial and error. The nature and structure of the proposed EPM is a simplified representation of the physical schemes and processes, but can nevertheless still provide accurate results. For example, where needed, the cropping patterns and water allocations suggested by EPM can be tested in detail by using the simulation models and a hydro-meteorological time series with a shorter time-step, and by incorporating the simulation of physical processes (such as the use of effective rainfall for cropping purposes, the soil moisture balance, and groundwater depletion). The simulation can provide feedback to the EPM in the form of more accurate estimation of the pumping costs based on the GSM estimated drawdown.

Because of the well-known high variability of the spatial and temporal distribution of hydrological events in arid and semi-arid areas, differential models with short time-span simulations have been used to represent the hydrological processes of the study area. With reasonable accuracy, the baseline water resources of the study area have been assessed. However, when the $2 \times \mathrm{CO}_{2}$ climate change scenario was included in the assessment of future available water resources, the accuracy of the assessment fluctuated as a result of insufficient representation of temporal variation of hydrological events (such as flooding) experienced over the study area. The monthly runoff data describe an average value for a highly variable wadi discharge, but they do not necessarily represent real surface water systems of the study area. For ephemeral wadis, flood duration is the controlling factor that determines the volume of groundwater recharge (Reeder et al. 1980). The shorter the flood duration, the less the recharge to aquifers. High floods will be partly lost to the sea (Alderwish \& Dottridge 1998).

Another limitation with GCMs that would affect selection of measures to be adapted is that the models predict significantly different outcomes, and it is not possible to determine which scenario best represents future conditions.

These limitations become more crucial under circumstances of scarce water resources and more complicated with the anticipated decrease in water resources under anthropogenically induced climate change and rapid growth; hence, any results should be considered preliminary, especially in application to the water resources of the nation of Yemen. M ore research is required to improve the results of GCMs and to cover other parts of the country.

\section{LITERATURE CITED}

Alderwish A, Dottridge J (1995a) Estimation of groundwater recharge from ephemeral Wadi flows using sparse data. In: Solutions 1995. Proceedings of the 26th IAH Congress, Edmonton, J une 1995. IAH, Kenilworth

Alderwish A, Dottridge J (1995b) Modeling the infiltration from ephemeral Wadi flows in the Sana'a Basin, Yemen. In: Younger $P$ (ed) Modeling river aquifer interactions. British Hydrological Society, Occasional Paper 6, Dept of Civil Engineering, University of Newcastle, p 4-16

Alderwish A, Dottridge J (1998) Recharge components in a semi-arid area: the Sana'a Basin, Yemen. In: Robins NS (ed) Groundwater pollution, aquifer recharge and vulnerability. Geological Society, London, Spec Publ 130, p 165-173

Atkins WS, Binnie CJ A (1984) Feasibility study for Wadi Bana and Abyan Delta Development project, Vol II, Annex A, Hydrology and water resources. Ministry of Agriculture and Agrarian Reform (MAAR), Aden

Feenstra J F, Short M (1996) Handbook on methods for climate change impact assessment and adaption strategies, Draft Version 1.3. October 1996. United Nations Environmental Programme (UNEP)/Institute for Environmental Studies (IUM), Amsterdam

Goodman AS (1984) Principles of water resources planning. Prentice Hall, Inc, Englewood Cliffs, NJ

Negenman AJ H (1995) Water resources Abyan Delta. Report WRAY-34. General Directorate of Hydrology (Yemen), Sana'a, and Netherlands Geological Survey (TNO), Delft

Reeder J , Freyberg L, Franzini I, Remson I (1980) Infiltration under rapidly varying surface water depths. Water Resour Res 16:97-104

SCS (Soil Conservation Service) (1964) A method of estimating volume and rate of runoff in small watersheds. Tech Publ 149. US Department of Agriculture, Washington, DC

SCS (Soil Conservation Service) (1972) National engineering handbook, Section 4, Hydrology. US Department of Agriculture, Washington, DC

TSHWC (Technical Secretariat of the High Water Council) (1993a) Assessment of available surface water resources and its present and future uses. Final Report, Vol III. UNDP/DESD Project YEM/88/001, Sana'a

TSHWC (1993b) Water resources management in the Tihama. Final Report, Vol X. UNDP/DESD Project YEM/88/001, Sana'a. Al-Hreer, Amman

van der Gun J (1991) Water resource assessment and management. Pilot study for Wadi Surdud. General Directorate of Hydrology (Yemen), Sana'a, and Netherlands Geological Survey (TNO), Delft 